\title{
Prominent role of basal slip during high temperature deformation of pure Mg polycrystals
}

\author{
${ }^{1}$ C.M. Cepeda-Jiménez*, ${ }^{1}$ J.M. Molina-Aldareguia, ${ }^{2}$ F. Carreño, ${ }^{1}$ M.T. Pérez-Prado \\ ${ }^{1}$ IMDEA Materials Institute, C/ Eric Kandel, 2, 28906 Getafe, Madrid, Spain \\ ${ }^{2}$ National Center for Metallurgical Research (CENIM-CSIC), Av. Gregorio del Amo, 8, \\ 28040 Madrid, Spain \\ *Corresponding author
}

\section{Abstract}

Several controversies regarding the mechanical behavior of $\mathrm{Mg}$ at moderate temperatures and quasi-static strain rates remain unsolved. In particular, the fundamental reasons behind the anomalous grain size dependence of the flow stress during power law slip-dominated creep as well as of the observed decrease of the strain anisotropy with increasing temperature are still unknown. This work aims to shed light on these two issues by bringing new experimental evidence obtained by EBSD-aided slip trace analysis. Two pure $\mathrm{Mg}$ polycrystals with average grain sizes $(d)$ of $36 \mu \mathrm{m}$ and $19 \mu \mathrm{m}$, and similar textures and grain boundary (GB) misorientation distributions were prepared by rolling and annealing and were subsequently tested in tension along the rolling direction (RD) at $150^{\circ} \mathrm{C}$ and $250^{\circ} \mathrm{C}$ and at $10^{-3} \mathrm{~s}^{-1}$. Their macroscopic mechanical response is related to the corresponding microstructure and texture evolution after straining, as well as to the frequency of slip traces corresponding to basal, prismatic and pyramidal $<\mathrm{c}+\mathrm{a}>$ systems. This work highlights the prominent role of basal slip during high temperature deformation of microcrystalline pure $\mathrm{Mg}$ and suggests that this enhanced basal activity might be key to rationalize the two controversies under scrutiny. Furthermore, the current study attests to the impact on slip activity of grain size-texture correlations and of percolation between grains that are favorably oriented for basal slip during high temperature deformation of pure $\mathrm{Mg}$.

Keywords: magnesium, high temperature, slip trace analysis, deformation mechanisms, grain size distribution, texture. 


\section{Introduction}

The enormous potential of $\mathrm{Mg}$ alloys for lightweighting was established early on in the $20^{\text {th }}$ century [1]. and a significant amount of research has been carried out over the last fifteen years in order to improve critical mechanical properties of these materials, namely, the mechanical strength, the room temperature formability and the high temperature creep resistance [2]. However, optimization of strategies to design the absolute best alloy and microstructure still rely on the resolution of several issues that remain, to date, controversial. This paper focuses, in particular, on addressing several unresolved matters pertaining the high temperature deformation of $\mathrm{Mg}$ that are presented in detail below.

First, the effect of grain size on the high stress creep behavior of $\mathrm{Mg}$ alloys is not clear. Creep plasticity of metallic materials has been modeled using the well-established phenomenological relationship between the steady-state strain rate $(\dot{\varepsilon})$ and the corresponding stress $(\sigma)[3]$ :

$$
\dot{\varepsilon}=A_{0} \exp \left[-\frac{Q_{c}}{k T}\right]\left(\frac{\sigma}{E}\right)^{n}
$$

where $A_{0}$ is a constant, $\mathrm{k}$ is Boltzmann's constant, $\mathrm{Q}_{\mathrm{c}}$ is the activation energy for creep, $\mathrm{E}$ is the Young's modulus, and $n$, the stress exponent, is constant over large temperature, stress and strain rate ranges. In particular, at moderate to relatively high strain rates and temperatures, $n$ may be 3 , usually associated with viscous glide of dislocations, or it may adopt values between 4 and 7 when the dominant mechanism is climb-controlled dislocation slip. Grain size changes are known to have a negligible effect on the elevated-temperature flow properties of metals creep deformed under such conditions $[3,4]$. Decreasing grain size usually leads to insignificant increases in the yield strength $\left(\sigma_{\mathrm{y}}\right)$ as the potency of grain boundaries as strengthening elements decreases dramatically with temperature $[5,6]$. 
However, several conflicting evidences have been published regarding the effect of grain size during power law creep in Mg alloys [7-14]. In particular, while some researchers confirm the insensitivity to grain size of the flow stress $[7,8]$, others report a non-negligible decrease in creep strength with decreasing grain size [9-15]. The currently divergent views on the effect of grain size on power law creep of $\mathrm{Mg}$ alloys have, to date, not been reconciled. For example, Vagarali and Langdon [7] comparing their own data with earlier works, confirm a very similar creep behavior of pure $\mathrm{Mg}$ with average grain sizes $(d)$ between $60 \mu \mathrm{m}$ and $100 \mu \mathrm{m}$ tested under conditions for which $n=5.2$. Similarly, Watanabe et al. [8] did not report any changes in the flow stress of the AZ31 alloy with $d$ values ranging from $180 \mu \mathrm{m}$ to $300 \mu \mathrm{m}$ and tested at $375^{\circ} \mathrm{C}$ at strain rates between $10^{-5} \mathrm{~s}^{-1}$ to $10^{-3} \mathrm{~s}^{-1}$, for which $\mathrm{n}=3$. In contrast, Kim et al. [9] revealed strengthening of an AZ31 alloy tested at temperatures higher than $300^{\circ} \mathrm{C}$ and strain rates between $10^{-4} \mathrm{~s}^{-1}$ to $10^{-3} \mathrm{~s}^{-1}(\mathrm{n}=5)$ when the grain size was increased from $11.5 \mu \mathrm{m}$ to $130 \mu \mathrm{m}$. A similar grain size strengthening effect was reported by Del Valle et al. [10] in an AZ31 alloy deformed under similar testing conditions when $d$ increased from $17 \mu \mathrm{m}$ to $40 \mu \mathrm{m}(\mathrm{n}=6-7)$. The mentioned unexpected anomalous grain size effect during creep regimes in which dislocation motion is the dominant deformation mechanism is also supported by experimental evidence provided in other works [11-15]. The origin of this phenomenon has still not been clarified.

A second controversial issue is the role played by pyramidal $<c+a>$ slip systems and grain boundary sliding (GBS) during deformation of magnesium alloys at moderate temperatures $\left(\mathrm{T} \approx 150^{\circ} \mathrm{C}-250^{\circ} \mathrm{C}\right)$ and quasi-static strain rates $\left(\dot{\varepsilon} \approx 10^{-3} \mathrm{~s}^{-1}\right)$. Both mechanisms allow accommodating deformation along the c-axis and, thus, the prevalence of one or the other has proven hard to distinguish under some testing conditions. This discussion originated by the observation of a dramatic drop in the strain 
anisotropy (r-value) of an AZ31 rolled sheet alloy deformed along the transverse direction (TD) from a room temperature value of 3.5 to about 1.5 at $200^{\circ} \mathrm{C}$ [16], which was consistently reported later by several authors [17-21]. Viscoplastic self-consistent modeling (VPSC) has confirmed that either an enhanced activity of pyramidal $<\mathrm{c}+\mathrm{a}>$ slip [16-18] or an increased contribution of GBS [19-21] could in theory account for the observed decrease of the r-value with temperature. Furthermore, the experimental difficulties associated with accurately estimating slip or GBS activity also do not facilitate the resolution of this open question. Transmission electron microscopy (TEM) has been often utilized to assess the nature of the active dislocations, but this method has inherent limitations [22], including the difficulty in sampling large volumes, the likelihood of removing dislocations during sample preparation as well as of damaging of the thin area by beam irradiation, which might bias the analysis. GBS activity has recently been investigated in a Mg AZ31 sheet alloy under the temperatures and strain rates of interest by the quantification of boundary shears along pre-designed grids placed on the specimen surface by focused ion beam (FIB) deposition of Ga atoms [17], by the analysis of surface relief using interferometric techniques [20], and by the in-situ observation of grain boundary cracking and of jogging of fiducial cracks in a scanning electron microscope (SEM) [18]. An enhanced contribution of GBS with increasing temperature was not observed. However, these methods also have limitations as grain boundary shearing and surface relief could also arise as a consequence of intergranular strain accommodation during dislocation slip-dominated deformation. The fundamental reason behind the observed decrease in r-value at moderate temperatures remains, therefore, unknown.

This work aims to contribute to the discussion on the remaining controversies about the mechanical behavior of pure $\mathrm{Mg}$ at moderate temperatures and quasi-static 
strain rates by adding further experimental evidence provided by the technique of electron back-scattered diffraction (EBSD)-assisted slip trace analysis. With that purpose, two $\mathrm{Mg}$ polycrystals with average grain sizes of $36 \mu \mathrm{m}$ and $19 \mu \mathrm{m}$ and relatively wide grain size distributions, carefully prepared by rolling and annealing, were tested at $150^{\circ} \mathrm{C}$ and $250^{\circ} \mathrm{C}$ and $10^{-3} \mathrm{~s}^{-1}$ and the variation of the mechanical behavior, of the texture, and of the frequency of basal and non-basal traces was evaluated as a function of temperature. A special effort was made to obtain a statistically relevant quantification of slip traces under all the conditions investigated. The effects of grain size distributions and of the emerging correlations between grain size and crystallographic orientation on the high temperature mechanical response of pure $\mathrm{Mg}$ are investigated. The results obtained are discussed on the light of the existing literature.

\section{Experimental procedure}

The material employed in the present work was commercial high quality pure magnesium (99.95\%), which was received as a $10 \mathrm{~cm}$ diameter ingot in the as-cast condition. Slabs of this as-received material with $\sim 10 \mathrm{~mm}$ in thickness were processed by hot rolling at $200^{\circ} \mathrm{C}$ using three passes, each of $50 \%$ reduction, until a final thickness of $\sim 3 \mathrm{~mm}$ was obtained. Subsequently, the rolled samples were annealed in order to stimulate controlled grain coarsening with the aim of generating two polycrystals with different average grain sizes $(d)$. In particular, the two annealing temperature/time combinations chosen $\left(400^{\circ} \mathrm{C} / 10 \mathrm{~min}\right.$ and $\left.300^{\circ} \mathrm{C} / 5 \mathrm{~min}\right)$ gave rise to two microstructures with $d=36 \mu \mathrm{m}$ and $d=19 \mu \mathrm{m}$, respectively. The dominant crystallographic orientations as well as the GB misorientation distributions remained very similar in both polycrystals. 
The microstructure and the texture of the two rolled and annealed pure $\mathrm{Mg}$ sheets were examined by EBSD and by X-ray diffraction (XRD). EBSD microtexture measurements were carried out using a Helios NanoLab 600i FEI field emission gun scanning electron microscope (FEGSEM) equipped with a NordlysMax detector, a CCD camera, the AZtekHKL data acquisition software and the Channel 5.0 post-processing analysis package. The FEGSEM operating conditions were an accelerating voltage of $15 \mathrm{kV}$ and a current of $2.7 \mathrm{nA}$. The step size was varied as a function of the grain size (1.5 $\mu \mathrm{m}$ was used for the polycrystal with $d=19 \mu \mathrm{m}$ and $2.5 \mu \mathrm{m}$ for the polycrystal with $d=36 \mu \mathrm{m})$. Average grain size values were calculated by the linear intercept method from inverse pole figure maps (IPF) in the normal direction to the rolling plane (ND) considering only GBs with misorientation angles greater than $15^{\circ}$ and using a factor of 1.74. The macrotexture of the two processed samples was measured by the Schulz reflection method using a Philips X'pert-Pro Panalytical X-ray diffractometer furnished with a PW3050/60 goniometer and filtered $\mathrm{Cu} \mathrm{K} \alpha$ radiation. The surface area examined was about $1 \mathrm{~cm}^{2}$. XRD data were corrected for background and defocusing using the Philips X'pert software. From the incomplete measured pole figures the orientation distribution function (ODF) and, then, the complete calculated pole figures were constructed using the MTEX package [23].

The mechanical response until failure under tension along $\mathrm{RD}$ of the two pure $\mathrm{Mg}$ polycrystals at temperatures of $150^{\circ} \mathrm{C}$ and $250^{\circ} \mathrm{C}$ and at a constant crosshead displacement rate corresponding to an initial strain rate of $\sim 10^{-3} \mathrm{~s}^{-1}$ was measured using a Kammrath \& Weiss screw-driven tensile stage placed inside a Zeiss EVO MA15 SEM. The testing temperature was reached and maintained using a tungsten-based heater located just below the gage section of the sample. The temperature was 
monitored by a K-type thermocouple that was placed against the gage section of each sample.

A second set of tensile tests along RD was carried out in the two polycrystals investigated at $150^{\circ} \mathrm{C}$ and $250^{\circ} \mathrm{C}$ and at a constant crosshead displacement rate corresponding to an initial strain rate of $\sim 10^{-3} \mathrm{~s}^{-1}$ until strains of $10 \%$, at which a careful slip trace analysis was carried out following the methodology described below. For these tests, one surface of the tensile coupons was mirror-polished using increasingly finer diamond pastes and, finally, a colloidal silica slurry. Surface finishing consisted on a chemical polish for $5 \mathrm{~s}$ with a solution comprising $12 \mathrm{ml} \mathrm{HCl,} 8 \mathrm{ml} \mathrm{HNO}_{3}$ and $100 \mathrm{ml}$ methanol. The activation of the different slip systems during tensile testing at $150^{\circ} \mathrm{C}$ and $250^{\circ} \mathrm{C}$ was examined in the two polycrystals investigated by EBSD-assisted slip trace analysis $[18,24]$. This approach consists of the following steps. First, several large areas within the gage length of the tensile specimens are mapped by EBSD prior to testing. Next, samples are loaded and the evolution of the surface within the large EBSDmapped areas is followed by SEM imaging. In particular, special attention is paid to capturing the appearance of slip traces in as many grains as possible during deformation. The low pressure in the SEM chamber during the tensile tests is critical to avoid surface oxidation, which would severely hinder the observation of slip traces. Subsequently, tests are stopped at a selected strain and post-mortem EBSD examination of the same selected large areas is carried out with the aim of acquiring the final orientations of the grains in which slip traces were noticed. Finally, the assignment of each slip trace detected by SEM examination to a specific slip system is carried out by inputting the Euler angles of the corresponding grain (measured from the post-mortem EBSD maps) into a MATLAB code which provides as output a visual representation of all the possible plane traces corresponding to that particular orientation [25]. 
Comparison of the slip trace under study with those simulated by the code allows selecting the actual active slip system. Table 1 summarizes the number of slip traces analyzed in each of the two polycrystals deformed at $150^{\circ} \mathrm{C}$ and $250^{\circ} \mathrm{C}$. In general only one slip trace (or one set of parallel slip traces) was detected for each grain. The Schmid factors (SF) for the slip systems found to be active in each grain were calculated taking into account the corresponding pre-test EBSD-determined Euler angles and under the assumption of uniaxial tension along RD.

Finally, strain-rate-change (SRC) tensile tests was performed at $250^{\circ} \mathrm{C}$ in a universal Instron 1362 machine equipped with a four-lamp ellipsoidal furnace to determine the apparent stress exponent, $n_{a p}$, which was directly calculated from the experimental data using the following relation:

$$
n_{a p}=\left.\frac{\partial \ln \dot{\varepsilon}}{\partial \ln \sigma}\right|_{T}
$$

The following schedule of strain rates was utilized. The initial strain rate was $10^{-3} \mathrm{~s}^{-1}$. A first strain rate jump down to $3 \times 10^{-4} \mathrm{~s}^{-1}$ was performed after a plastic deformation of $\sim 10 \%$. Then, the strain rate was consecutively reduced down to $10^{-4}, 3 \times 10^{-5}, 10^{-5}$ and $3.10^{-6} \mathrm{~s}^{-1}$. The material was allowed to flow for strains ranging from $2 \%$ to $4 \%$ at each step. Subsequently, the strain rate was again consecutively increased in five steps (using the same strain rates mentioned above) up to $10^{-3} \mathrm{~s}^{-1}$, as a check on the repeatability of flow stress measurements and in order to verify that no noticeable changes in grain size occurred during straining at the low strain rates. More details about the SRC tests can be found elsewhere [15].

All the mechanical tests were performed in dog-bone tensile samples with 10 $\mathrm{mm}$ gage length and a transversal section of $2 \times 2.5 \mathrm{~mm}^{2}$ that were electrodischargemachined with the tensile axis parallel to the rolling direction (RD). 


\section{Results and discussion}

3.1 High temperature macroscopic mechanical response under tension at moderate temperatures and quasi-static rates.

Fig.1 illustrates the microstructure and the texture of the two polycrystals under study, with $d$ values of $36 \mu \mathrm{m}$ and $19 \mu \mathrm{m}$, respectively. The EBSD IPF maps in the ND are shown next to the corresponding XRD macrotextures $(\{0001\}$ and $\{10 \overline{1} 0\}$ pole figures) and misorientation ( $\theta$ ) distribution histograms. Fig. 1 highlights the resemblance of the macro and meso-texture of the two designed microstructures, both exhibiting similar basal fiber textures and a maximum frequency of GBs with $\theta=30^{\circ}$.

The tensile true stress-true strain curves belonging to tests along RD performed to failure at $150^{\circ} \mathrm{C}$ and $250^{\circ} \mathrm{C}$ and at an initial strain rate of $10^{-3} \mathrm{~s}^{-1}$ are plotted in Fig. 2. It is shown for each of the two polycrystals that, as expected, raising the test temperature gives rise to a decrease in the flow stress and an increase in ductility. However, at a given test temperature, the flow stress for the finer-grained sample falls below that of the coarser. This softening with decreasing grain size during testing at quasi-static rates and moderate temperatures has been reported earlier in Mg alloys [915] and no consensus has been reached as to the fundamental basis for this phenomenon. The present study aims to bring further experimental evidence that helps to elucidate this matter.

The work hardening behavior (WH) of the two investigated pure $\mathrm{Mg}$ polycrystals has been analyzed by means of the macroscopic WH rate, $\theta=d \sigma / d \varepsilon$, where $\sigma$ and $\varepsilon$ are the macroscopic true stress and true plastic strain, respectively. The representation of $\theta\left(\sigma-\sigma_{0.2}\right)$ vs. $\left(\sigma-\sigma_{0.2}\right)$ (Fig. 3), which provides information on the dislocation evolution, shows near parabolic curves for all the investigated conditions and a clear decrease of the rate of dislocations' storage with decreasing grain size. It 
must be mentioned that, notably, work hardening decreases abruptly at $150^{\circ} \mathrm{C}$ when $d$ decreases from $36 \mu \mathrm{m}$ to $19 \mu \mathrm{m}$. At $250^{\circ} \mathrm{C}$ very low $\mathrm{WH}$ rates are observed irrespective of grain size.

Fig. 4 compares the EBSD IPF maps in the ND and the corresponding $\{0001\}$ pole figures of selected areas of the two polycrystals under study prior to testing and after a strain of $\sim 10 \%$ at $250^{\circ} \mathrm{C}$. Some cracks became apparent at the grain boundaries of the strained samples as non-indexed points, especially for the finer-grained microstructure $(d=19 \mu \mathrm{m})$, where it seems that strain tends to concentrate along deformation bands. Most importantly, it is evidenced in Fig. 4 that the grains remain fairly unchanged after tensile testing at $250^{\circ} \mathrm{C}$. In addition, the initial strong basal texture is retained after deformation. Altogether, these observations confirm the thermal stability of the investigated microstructures and indicate that dynamic processes, such as ab-normal coarsening or dynamic recrystallization (DRX), do not take place during tensile testing under the selected conditions.

\subsection{High temperature slip activity.}

An exhaustive EBSD-aided slip trace analysis was carried out at approximately $10 \%$ strain with the aim of inferring the effect of temperature on the incidence of the different deformation systems during tension along $\mathrm{RD}$ in the two pure Mg polycrystals under study. For each sample, large areas were inspected, as shown in the EBSD IPF maps of Fig. 1 and 4 . The frequency of basal and non-basal traces is plotted as a function of the average grain size in Fig. 5. Several trends may be inferred from this figure. At $150^{\circ} \mathrm{C}$, in the coarser polycrystal, $97 \%$ of the traces corresponded to nonbasal slip while the contribution of basal slip was observed to be minimal $(\sim 3 \%$ of traces). The dominance of non-basal slip systems during in-plane tension of coarsegrained rolled $\mathrm{Mg}$ sheets is in full agreement with previous modeling studies [16,26- 
29]. The limited activity of basal systems has been attributed to the low average Schmid factor for basal slip (in the polycrystal with $d=36 \mu \mathrm{m}, \mathrm{SF}_{\text {basal }}=0.205$ ). However, in the finer-grained polycrystal, at the same testing temperature $\left(150^{\circ} \mathrm{C}\right)$, only $26 \%$ of all detected traces corresponded to non-basal slip and $\sim 74 \%$ to basal systems. The remarkable differences in slip activity observed between the two pure $\mathrm{Mg}$ samples investigated attest to the tremendous influence of GBs in the deformation of polycrystals with microcrystalline grain sizes. In a previous work [30] a clear transition from non-basal to basal slip-dominated flow was observed to occur at temperatures close to room temperature $\left(50^{\circ} \mathrm{C}\right)$ when $d$ decreased below $36 \mu \mathrm{m}$. This change in slip activity was shown to be consistent with an increase in the $\mathrm{CRSS}_{\text {non-basal }} / \mathrm{CRSS}_{\text {basal }}$ ratio with decreasing $d$, due to a stronger GB strengthening of non-basal systems. The current results suggest that the influence of GBs is still strong at $150^{\circ} \mathrm{C}$.

When the testing temperature is raised from $150^{\circ} \mathrm{C}$ to $250^{\circ} \mathrm{C}$, apparently contradicting changes in the slip activity are observed in the two polycrystals. In particular, while in the coarser polycrystal $(d=36 \mu \mathrm{m})$ the frequency of non-basal traces decreases from $97 \%$ to $60 \%$ and the frequency of basal traces increases from $3 \%$ to $40 \%$, in the finer-grained polycrystal $(d=19 \mu \mathrm{m})$ the frequency of non-basal traces increases from $26 \%$ to $42 \%$ and the frequency of basal traces decreases from $74 \%$ to $58 \%$. These observations may be rationalized as follows.

\subsubsection{Influence of grain size-texture correlations and grain size distributions.}

Let's first analyze the changes in slip activity observed in the coarser polycrystal. Fig. 6 illustrates the SF distributions with respect to the global external stress corresponding to the pyramidal $<\mathrm{c}+\mathrm{a}>$, prismatic and basal traces detected in the coarser $\mathrm{Mg}$ polycrystals after deformation at $250^{\circ} \mathrm{C}$, together with a $\{0001\}$ discrete pole figure showing the orientation of the c-axes of grains with pyramidal $<\mathrm{c}+\mathrm{a}>$ (blue 
dots), prismatic (red dots) and basal (green dots) traces. It can be seen that a significant portion of the pyramidal $<\mathrm{c}+\mathrm{a}>$ slip traces were detected in grains with low $\mathrm{SF}$, indicating that they were not activated in response to the applied stress. This is consistent with the well-known role of pyramidal $<\mathrm{c}+\mathrm{a}>$ slip in the accommodation of strains at GBs (non-Schmid slip activation) [2]. However, the high SFs of most basal traces reveal that basal slip did become active in response to the applied stress. These changes in slip activity do not appear to be consistent with earlier studies on the thermal activation of the different deformation modes in single crystals [31,32], which report that $\mathrm{CRSS}_{\text {non-basal }}$ decreases with increasing temperature and that basal slip is athermal at $\mathrm{T}>25^{\circ} \mathrm{C}$, which would give rise to an enhanced contribution of non-basal slip at higher temperatures. In the following we will show how the observed promotion of basal slip in the coarser polycrystal at $250^{\circ} \mathrm{C}$ (Fig. 5) may, instead, result from the presence of grain size-texture correlations (see below) as well as from the relaxation of constraints imposed to grains favorably oriented for basal slip by their neighbors (section 3.2.2).

Fig. 7 illustrates the grain size distribution corresponding to the polycrystal with $d=36 \mu \mathrm{m}$. This positively skewed unimodal distribution follows approximately a statistical log-normal density probability function, in agreement with previous experimental works [33-36] and modeling studies of normal grain growth [37,38]. The size of individual grains (D) ranges from $3 \mu \mathrm{m}$ to $\sim 200 \mu \mathrm{m}$. The width of the distribution is often represented by the parameter $\sigma_{0} / \mu$, which may be calculated by the following expression:

$$
\frac{\sigma_{0}}{\mu}=\sqrt{\exp \left(S^{2}\right)-1}
$$

where $\mathrm{S}$ is the standard deviation of the distribution of the logarithms of the grain sizes $(\operatorname{Ln}(\mathrm{D}))$. In the pure $\mathrm{Mg}$ polycrystal with $d=36 \mu \mathrm{m}, \sigma_{0} / \mu \sim 1.1$, which is a high value compared to the widths of lognormal distributions measured experimentally in previous 
works, which range between 0.3 and 1 [33-36]. A few modeling studies have analyzed the impact of grain size distributions on the mechanical response of polycrystalline materials [39-43]. In general, it is commonly believed that, at low temperatures, HallPetch strengthening results in the larger grains having lower yield stresses and, thus, deforming more than the finer grains. However, at higher temperatures, GB strengthening effects become less important and thus strain is distributed more homogeneously throughout the entire grain population. Fig. 8 illustrates the EBSD IPF maps in the ND as well as the $\{0001\}$ EBSD pole figures corresponding to grains with sizes (D) larger (Fig. 8a) and smaller (Fig. 8b) than the average value ( $d=36 \mu \mathrm{m})$. It can be seen that the basal texture is significantly stronger in the coarser than in the finer grains ( $I_{\max }=15$ and 10, respectively). This is consistent with the preferential growth of grains with c-axes close to ND during the post-rolling annealing treatment, which has often been observed in $\mathrm{Mg}$ alloys [44]. Fig. 8 reveals, thus, the presence of a remarkable correlation between the grain size and the crystallite orientations. Finer grains tend, on average, to have their c-axes more tilted away from ND or, in other words, to be more favorably oriented for basal slip. More specifically, $\mathrm{SF}_{\text {basal }}$ is 0.188 when $\mathrm{D}>d$ and 0.223 when $\mathrm{D}<d$. Grain size-texture correlations have been observed earlier in hcp $\alpha$-Ti [45]. Fig. 9 plots the distribution of grain sizes (D) in which non-basal and basal traces where detected in the polycrystal with $d=36 \mu \mathrm{m}$ tested at $250^{\circ} \mathrm{C}$. The average grain size for non-basal systems $\left(d_{\text {non-basal }}\right)$ is $56 \mu \mathrm{m}$, while $d_{\text {basal }}=46 \mu \mathrm{m}$. The observed enhanced basal slip activity at $250^{\circ} \mathrm{C}$ in the coarser polycrystal may, thus, be influenced by the higher contribution of fine grains to strain with increasing temperature.

In the polycrystal with $d=19 \mu \mathrm{m}$ the frequency of non-basal traces increases from $\sim 26 \%$ to $\sim 42 \%$ when the testing temperature is raised from $150^{\circ} \mathrm{C}$ to $250^{\circ} \mathrm{C}$ and, consequently, the frequency of basal traces decreases from $74 \%$ to $58 \%$. Fig. 10 depicts 
the distribution of SFs corresponding to the non-basal and basal traces detected in the finer-grained polycrystal after testing at $250^{\circ} \mathrm{C}$ together with a $\{0001\}$ discrete pole figure showing the orientation of the c-axes of grains with pyramidal $<\mathrm{c}+\mathrm{a}>$ (blue dots), prismatic (red dots) and basal (green dots) traces. It can be seen that most slip traces have relatively large SFs, i.e., most slip systems are activated in response to the applied stress, but also a non-negligible fraction of pyramidal slip traces are non-Schmid effects. Fig. 11 illustrates the unimodal log-normal grain size distribution corresponding to this polycrystal, for which $\sigma_{0} / \mu$ is 0.82 . Fig. 12 illustrates the EBSD IPF maps in the ND as well as the $\{0001\}$ EBSD pole figures corresponding to grains with sizes (D) larger (Fig. 12a) and smaller (Fig. 12b) than the average value ( $d=19 \mu \mathrm{m})$. It is evident that a correlation between the grain size and the crystallographic orientation is also present in this polycrystal. In particular, finer grains tend to have c-axes more tilted away from ND than coarser grains $\left(\mathrm{SF}_{\text {basal }}\right.$ is 0.167 when $\mathrm{D}>d$ and 0.194 when $\left.\mathrm{D}<d\right)$. In order to determine whether the grain size distribution has a noticeable effect in the high temperature deformation of this polycrystal, the distribution of grain sizes (D) corresponding to non-basal and basal traces after testing at $250^{\circ} \mathrm{C}$ is plotted in Fig. 13. The average grain size for non-basal systems $\left(d_{\text {non-basal }}\right)$ is $23 \mu \mathrm{m}$, while $d_{\text {basal }}$ is equal to $25 \mu \mathrm{m}$. The small difference found between $d_{\text {non-basal }}$ and $d_{\text {basal }}$, which could well be within the error of the measurement, suggests that grain size distribution effects are negligible in the finer grained polycrystal. In the absence of grain size distribution effects, the promotion of non-basal slip at $250^{\circ} \mathrm{C}$ must be attributed to the thermal activation of prismatic and pyramidal systems, in agreement with previous experimental and modeling works in single crystals [31,32]. However, it must be noted that, despite the dramatic decrease in the $\mathrm{CRSS}_{\text {non-basal }} / \mathrm{CRSS}_{\text {basal }}$ ratio at the temperatures of interest 
[31], the increase in non-basal activity is only moderate $(\sim 16 \%)$. This suggests that additional microstructural features might also influence slip activity (see section 3.2.2).

The effects of grain size distributions on the mechanical behavior of metals have been scarcely studied experimentally to date and only some modeling efforts have been devoted to clarify this issue [39-43]. In general, they are known to be stronger for wider distributions and smaller mean grain sizes, which promote larger elastoplastic transitions. The smaller impact of the grain size distribution in the finer-grained polycrystal, in comparison with the coarser one, could be consistent with the presence of a smaller width $\left(\sigma_{0} / \mu\right)$ of the grain size distribution $(0.82$ vs 1.1$)$.

\subsubsection{Influence of percolation between grains favorably oriented for basal slip.}

Figs. $14 \mathrm{a}$ and $14 \mathrm{~b}$ illustrate, respectively, the EBSD of grains which are well oriented for basal slip in the polycrystals with $d=36 \mu \mathrm{m}$ and $d=19 \mu \mathrm{m}$ in the asprocessed condition. More specifically, these maps include grains with $\mathrm{SF}_{\text {basal }}>0.2$, as they are the ones in which basal activity was detected, as shown in Figs. 6 and 10. The misorientation distribution histograms are plotted next to the corresponding EBSD maps. It was shown in a recent work [30] that propagation of basal slip in pure magnesium polycrystals was blocked in boundaries with misorientation angles larger than approximately $35^{\circ}$. The degree of "connectivity" (percolation) between the grains of the maps of Figs. 14a and 14b may, thus, be roughly assessed by calculating the fraction of boundaries with misorientation angles smaller than $35^{\circ}\left(f_{\theta^{<35}}\right)$, i.e., by integrating the corresponding sections of the misorientation distribution histograms. The $f_{\theta<35}$ values obtained for the polycrystals with $d=36 \mu \mathrm{m}$ and $d=19 \mu \mathrm{m}$ are, respectively, $56 \%$ and $67 \%$. The difference between these two values might have several implications. First, the decrease in the connectivity of grains that are well oriented for 
basal slip with increasing grain size might explain why, at lower temperatures $\left(150^{\circ} \mathrm{C}\right)$, non-basal slip activity dominates deformation in the coarser polycrystal while basal slip is the main contributor to strain in the finer-grained polycrystal. Second, it seems logical that, with increasing temperature, the constraints imposed in grains that are well oriented for basal slip by their neighbors become gradually relaxed, thus, leading to the promotion of basal slip at the highest temperatures investigated. Fig. 15 illustrates two representative SEM micrographs corresponding to the polycrystals with $d=36 \mu \mathrm{m}$ and $d=19 \mu \mathrm{m}$ after tensile straining at $250^{\circ} \mathrm{C}$. In particular, surface areas in which basal slip traces were detected are shown. It can be seen that, indeed, transfer of basal slip across boundaries becomes relatively common, leading even to the formation of basal slip bands traversing a large number of grains in the finer-grained polycrystal. In summary, the relaxation of percolation effects on basal slip might contribute to the observed enhancement of basal slip in the coarser polycrystal at $250^{\circ} \mathrm{C}$ as well as to the absence of a dramatic decrease in basal slip activity in the finer-grained polycrystal at this same temperature.

\subsection{Origin of the anomalous softening with grain refinement during dislocation} mediated power law creep.

Several contradictory evidences have been published regarding the effect of grain size during power law creep in Mg alloys [7-15]. Overall, in microstructures with grain sizes larger than about $60 \mu \mathrm{m}$, the flow stress is observed to be rather insensitive to $d[7,8]$, in agreement with well-accepted models of dislocation slip-mediated power law creep $(n=3-7)[3,4]$. However, an anomalous softening with decreasing grain size has been consistently reported for $d$ values smaller than approximately $40 \mu \mathrm{m}$ [9-15] and it has also been evidenced in the current study of pure Mg polycrystals when the average grain size decreased from $36 \mu \mathrm{m}$ to $19 \mu \mathrm{m}$ (Fig. 2). 
The two explanations that have been put forward to explain this phenomenon include and enhancement of DRX [14] as well as of GBS and multiple slip with decreasing grain size [15]. In the following, the plausibility of these two arguments to rationalize the softening observed in the current study is discussed. First, as illustrated in Fig. 4, the microstructure of the two polycrystals investigated remains very stable during testing up to temperatures of $250^{\circ} \mathrm{C}$, and thus DRX must be ruled out as the origin of the observed softening with grain refinement. Second, since it is well known that GBS activation leads to significant increases in ductility [46], an enhanced contribution of GBS with temperature in the finest microstructure does not seem consistent with the fact that, as revealed in Fig. 2 , at $250^{\circ} \mathrm{C}$, the ductility decreases with decreasing grain size.

In order to better assess whether GBS has a significant contribution to strain, an analysis of the apparent stress exponents, $n_{a p}$, measured in the two pure $\mathrm{Mg}$ polycrystals from SRC tests at $250^{\circ} \mathrm{C}$, was carried out, and the results are shown in Fig. 16. The logarithm of $\dot{\varepsilon}$ is represented in Fig. 16a as a function of the logarithm of the true flow stress, $\sigma$, for the two microstructures investigated. In addition, Fig. 16b shows the variation of $n_{a p}$ with the strain rate $(\dot{\varepsilon})$. The minimum and maximum apparent stress exponents calculated for each sample have been indicated in Fig. 16a. It must be noted here that the occurrence of microstructural instabilities during SRC tests can be ruled out because a perfect coincidence was found between $\dot{\varepsilon}-\sigma$ pairs measured during the downward and upward strain rate steps [47]. Fig. 16 reveals a gradual reduction of the stress exponent as $\dot{\varepsilon}$ decreases from $10^{-3} \mathrm{~s}^{-1}$ to $10^{-5} \mathrm{~s}^{-1}$ for the two polycrystals investigated. In particular, in the coarsest microstructure $(d=36 \mu \mathrm{m}), n_{a p}$ decreases from 8 to 3.6 while in the finest one $(d=19 \mu \mathrm{m})$ the $n_{a p}$ values range from 6.2 to 3.2 . Several conclusions may thus be drawn from Fig. 16. First, at the relatively elevated strain rate 
at which the constant crosshead speed tests of Fig. 2 were performed $\left(10^{-3} \mathrm{~s}^{-1}\right)$ and, in fact, at all strain rates higher than $\sim 10^{-4} \mathrm{~s}^{-1}, n_{a p}$ values are higher than 5 in both polycrystals which, according to the currently well-established understanding of creep $[3,4]$, clearly indicates that deformation is dominated by dislocation slip and, thus, that the contribution of GBS is expected to be minimal. Second, the anomalous softening with decreasing grain size observed during constant crosshead speed tests (Fig. 2) at an initial rate of $10^{-3} \mathrm{~s}^{-1}$ is also apparent at all the strain rates for which creep is controlled by dislocation slip. Third, the stress exponent is always lower in the finer-grained polycrystal. This is consistent with the work of Del Valle et al. [15], who observed that $n_{a p}$ decreased from 9.8 to 6.8 in a rolled AM60 alloy when the grain size decreased from 23.5 to $17 \mu \mathrm{m}$ at $250^{\circ} \mathrm{C}$ and relatively high strain rates. Finally, an increased contribution of GBS may indeed occur at strain rates of $\approx 10^{-5} \mathrm{~s}^{-1}$ (two orders of magnitude smaller than those of the constant crosshead speed tests of the present study) as suggested by the reduction in $n_{a p}$ down to values approaching 3 [48].

Altogether, the microstructure and mechanical property measurements reported above suggest that the origin of the anomalous softening observed here in pure $\mathrm{Mg}$ at moderate temperatures and relatively high quasi-static strain rates, where dislocation slip controls deformation, can't be attributed to either the enhancement of DRX or of GBS. Instead, it is our contention that this effect is due to the observed increased activity of basal slip with decreasing grain size (Fig. 5). The higher ductility at $250^{\circ} \mathrm{C}$ of the polycrystal with $d=36 \mu \mathrm{m}$ could be attributed to the more balanced activation of basal, prismatic and pyramidal $<\mathrm{c}+\mathrm{a}>$ systems.

Earlier works have demonstrated a strong influence of texture on the slipdominated creep behavior of Mg alloys [11, 49-52] and, in particular, have shown that an increased contribution of basal slip leads to softening. For example, Del Valle et al 
[15] reported that the flow stress of an AM60 Mg alloy processed by equal channel angular pressing (ECAP) was approximately 30\% lower than that of the same alloy processed by rolling, even though both specimens had a similar grain size of 18-20 $\mu \mathrm{m}$. This was attributed to the presence of a larger fraction of grains favorably oriented for basal slip in the ECAP-processed samples. Thus, the current study suggests that a reduction in grain size in rolled $\mathrm{Mg}$ has an equivalent effect to that obtained by altering the texture while keeping a constant grain size.

The conflicting evidences reported in the literature regarding the influence of grain size on the flow stress during power law dislocation mediated creep [7-15] may, then, be rationalized as follows. In coarse grained polycrystals non-basal slip plays a dominant role at moderate temperatures and intermediate strain rates and, thus, no significant changes in the flow stress with grain size are expected, in agreement with earlier works $[7,8]$. However, when the average grain size decreases below a critical value, the contribution of basal slip to deformation increases gradually, leading to the observed softening and to a decrease in the stress exponents.

\subsection{Origin of the decrease in strain anisotropy with increasing temperature}

Inferring the activity of different deformation mechanisms from the variation of the r-value at a specific strain is not a straightforward task since there might be a relatively large inherent error in the measurements, which can be influenced by many factors, including specimen geometry and size. However, despite these observations must be taken with caution, a general consensus exists about the reduction in r-value in $\mathrm{Mg}$ rolled alloys, tested in tension at quasi-static rates $\left(\sim 10^{-3} \mathrm{~s}^{-1}\right)$, when the temperature is raised from RT to approximately $200^{\circ} \mathrm{C}$, which has been repeatedly reported for specimens with average grain sizes from 47 to $2 \mu \mathrm{m}$ [16-21]. The current work suggests that, at least in the samples with moderate to large grain sizes $(\mathrm{d}>10-15 \mu \mathrm{m})$ the origin 
of the decrease in the r-value might lie in the relatively balanced contribution of basal and non-basal systems to deformation.

\section{Conclusions}

This research aims to contribute to the discussion of several remaining controversies regarding the high temperature mechanical behavior of $\mathrm{Mg}$. With that purpose, two pure $\mathrm{Mg}$ polycrystals were rolled and annealed at the appropriate conditions to design two microstructures with $d$ values of $36 \mu \mathrm{m}$ and $19 \mu \mathrm{m}$, and similar textures and misorientation distributions. Subsequently these two polycrystals were tested in tension along $\mathrm{RD}$ at $150^{\circ} \mathrm{C}$ and $250^{\circ} \mathrm{C}$ and at $10^{-3} \mathrm{~s}^{-1}$ and the incidence of basal, prismatic and pyramidal $<\mathrm{c}+\mathrm{a}>$ slip was estimated by EBSD-aided slip trace analysis for all the testing conditions investigated. Slip activity was related to the corresponding macroscopic mechanical response as well as to the texture and microstructure evolution. The following conclusions may be drawn from this study:

1. An anomalous decrease of the flow stress with decreasing grain size was observed during tension along $\mathrm{RD}$ at the two temperatures investigated $\left(150^{\circ} \mathrm{C}\right.$ and $250^{\circ} \mathrm{C}$ ), at which creep is dominated by dislocation slip and where the stress exponents are higher than 5. Simultaneously, WH decreases abruptly with decreasing grain size.

2. At $150^{\circ} \mathrm{C}$ a transition from non-basal to basal dominated flow takes place when $d$ decreases from $36 \mu \mathrm{m}$ to $19 \mu \mathrm{m}$. This is consistent with earlier studies, which reported an increase in the $\mathrm{CRSS}_{\text {non-basal }} / \mathrm{CRSS}_{\text {basal }}$ ratio with decreasing $d$. The current results suggest that the influence of GBs is still strong at $150^{\circ} \mathrm{C}$.

3. At $250^{\circ} \mathrm{C}$ an increase of basal slip activity is observed in the coarsest polycrystal. It is shown that this is a manifestation of both grain size distribution and basal 
slip percolation effects. More specifically, it is attributed, first, to the effect of the existing remarkable grain size-texture correlations, whereby the finest grains in the distribution, which have a higher contribution to strain at high temperatures, are better oriented for basal slip and, second, to the relaxation of constraints imposed by neighbours to grains that are favourably oriented for basal slip.

4. In the finer-grained polycrystal, on the contrary, an increase of non-basal activity is observed at $250^{\circ} \mathrm{C}$. This is consistent with enhanced thermal activation of prismatic and pyramidal systems. The impact on the slip activity of the existing texture-grain size correlation, which is similar to that observed in the coarser polycrystal, is found to be smaller due to the narrower grain size distribution. The fact that, despite the dramatic decrease in the $\mathrm{CRSS}_{\text {non-basal }} / \mathrm{CRSS}_{\text {basal }}$ ratio at $250^{\circ} \mathrm{C}$, the reduction in basal slip activity is only moderate, may be attributed, again, to the relaxation of constraints imposed by neighbours to grains that are favourably oriented for basal slip. In fact, due to the higher degree of connectivity of grains that are favourably oriented for basal slip in this finer-grained polycrystal, increasing the temperature results in the formation of basal slip bands.

5. The above results may aid to rationalize the following controversies regarding the high temperature mechanical behaviour of $\mathrm{Mg}$ alloys. First, the anomalous softening with decreasing grain size within the dislocation-mediated creep regime, observed in the present study and reported consistently in the literature, may be attributed to the higher incidence of basal slip with grain refinement. Second, the decrease in the strain anisotropy (r-value) when the temperature is raised to approximately $200^{\circ} \mathrm{C}$, at least in samples with medium to large grain 
sizes, may result from a balance activity of basal, prismatic and pyramidal systems during straining.

\section{Acknowledgements}

The authors wish to acknowledge financial support from the European Commission (ExoMet Project, 7th Framework Programme, contract FP7-NMP3-LA-2012-280421). The technicians at the CAI Difracción de rayos X (Complutense University of Madrid) are also thanked for their assistance with macrotexture measurements.

\section{References}

1. Mordike BL, Ebert T. Mater Sci Eng 2001;302:37.

2. Advances in wrought magnesium alloys. Ed. by C. Bettles and M. Barnett. Cambridge:Woodhead publishing; 2012.

3. Kassner ME, Pérez-Prado MT. Fundamentals of Creep in Metals and Alloys. Oxford:Elsevier;2004.

4. Sherby OD, Burke PM. Prog Mater Sci 1968;13:323.

5. Kassner ME, Li X. Scripta Metall Mater 1991;25:2833.

6. Petkovic RA, Luton MJ, Jonas JJ. Metal Sci 1979;13:569.

7. Vagarali SS, Langdon TG. Acta Metall. 1981;29:1969.

8. Watanabe H, Tsutsui H, Mukai T, Kohzu M, Tanabe S, Higashi K. Int J Plast $2001 ; 17: 387$.

9. Kim WJ, Chung SW, Chung CS, Kum D. Acta Mater 2001;49:3337.

10. Del Valle JA, Pérez-Prado MT, Ruano OA. Metall Trans A 2005;36:1427.

11. Del Valle JA, Ruano OA. Mat Lett 2008;62:3391.

12. Spigarelli S, El Mehtedi M, Ciccarelli D, Regev M. Mater Sci Eng A 2011;528:6919.

13. Spigarelli S, Ruano OA, El Mehtedi M, Del Valle JA. Mater Sci Eng A 2013;570:135.

14. Barnett MR, Beer AG, Atwell D, Oudin A. Scripta Mater 2004;51:19.

15. Del Valle JA, Ruano OA. Acta Mater 2007;55:455.

16. Agnew SR, Duygulu O. Int J Plast 2005;21:1161.

17. Stanford N, Sotoudeh K, Bate PS. Acta Mater 2011;59:4866.

18. Boehlert CJ, Chen Z, Gutiérrez-Urrutia I, Llorca J, Pérez-Prado MT. Acta Mater 2012;60:1889. 
19. Hutchinson B, Barnett MR, Ghaderi A, Cizek P, Sabirov I. Int J Mater Res 2009; 100:556.

20. Barnett MR, Ghaderi A, Sabirov I, Hutchinson B. Scripta Mater 2009;61:277.

21. Atwell DL, Barnett MR, Hutchinson WB. Mater Sci Eng A 2012;549:1.

22. D. B. Williams, C. B. Carter, Transmission Electron Microscopy, Plenum Press, 1996.

23. Bachmann F, Hielscher R, Schaeber H. Solid State Phenomena 2010;160:63.

24. Boehlert CJ, Li H, Wang L, Bartha B. Adv Mater Process 2010;168:41.

25. Bieler TR, Eisenlohr P, Roters F, Kumar D, Mason DE, Crimp MA, Raabe D, Int J Plasticity 2009;25:1655.

26. Del Valle JA, Carreño F, Ruano OA. Acta Mater 2006;54:4247.

27. Agnew SR, Yoo MH, Tomé CN. Acta Mater. 2001;49:4277.

28. Wang H, Raeisinia B, Wu PD, Agnew SR, Tomé CN. Int J Solids Struct 2010;47:2905

29. Proust G, Tomé CN, Jain A, Agnew SR. Int J Plast 2009;25:861.

30. Cepeda-Jiménez CM, Molina-Aldareguia JM, Pérez-Prado MT. Acta Mater 2014, In Press.

31. Barnett MR. Metall Mater Trans A 2003;34:1799.

32. Chapuis A, Driver JH. Acta Mater 2011;59:1986.

33. Okazaki K, Conrad H. Trans JIM 1972;13:198.

34. Krill CE, Birringer R. Phil Mag A 1998;77:621.

35. Zhilyaev AP, Gubicza J, Nurislamova G, Revesz A, Surinach S, Baro MD, Ungar T. Phys Stat Sol A 2003;198:263.

36. Rhines FN, Patterson BR. Metall Trans A 1982;13:985.

37. Feltham P. Acta Metal 1957;5:97.

38. Kurtz SK, Carpay FMA. J Appl Phys 1980;51:5725.

39. Kurzydlowski KJ. Scripta Metal Mater 1990;24:879.

40. Berbenni S, Favier V, Berbeiller M. Int J Plast 2007;23:114.

41. Raeisinia B, Sinclair CW, Poole WJ, Tomé CN. Modell Simul Mater Sci Eng 2009; $16: 1$.

42. Nicaise N, Berbenni S, Wagner F, Berveiller M, Lemoine X. Int J Plast 2011;27:232.

43. B. Raeisinia. Modelling the effect of grain size distribution on the mechanical response of metals. PhD thesis, University of British Columbia, 2008.

44. Pérez-Prado MT, Ruano OA. Scripta Mater 2003;48:59.

45. Fromm BS, Adams BL, Ahmadi S, Knezevic M. Acta Mater 2009;57:2339. 
46. Nieh TG, Wadsworth J, Sherby OD. Superplasticity in metals and ceramics. Cambridge University Press; 1997.

47. Carreño F, Ruano OA. Acta Mater. 1998;46:159.

48. Metenier P, González-Doncel G, Ruano OA, Wolfenstine J, Sherby OD. Mater Sci Eng A. $1990 ; 125: 195$.

49. Hsu S, Edwards GR, Sherby OD. Acta Metall 1983;31:763.

50. Edwards GR, McNelley TR, Sherby OD. Scripta Metall 1974;8:475.

51. Kaibyshev OA, Kazachkov IV, Salikhov SY. Acta Metall 1978;26:1887.

52. Watanabe H, Takara A, Somekawa H, Mukai T, Higashi K. Scripta Mater 2005;52:449. 


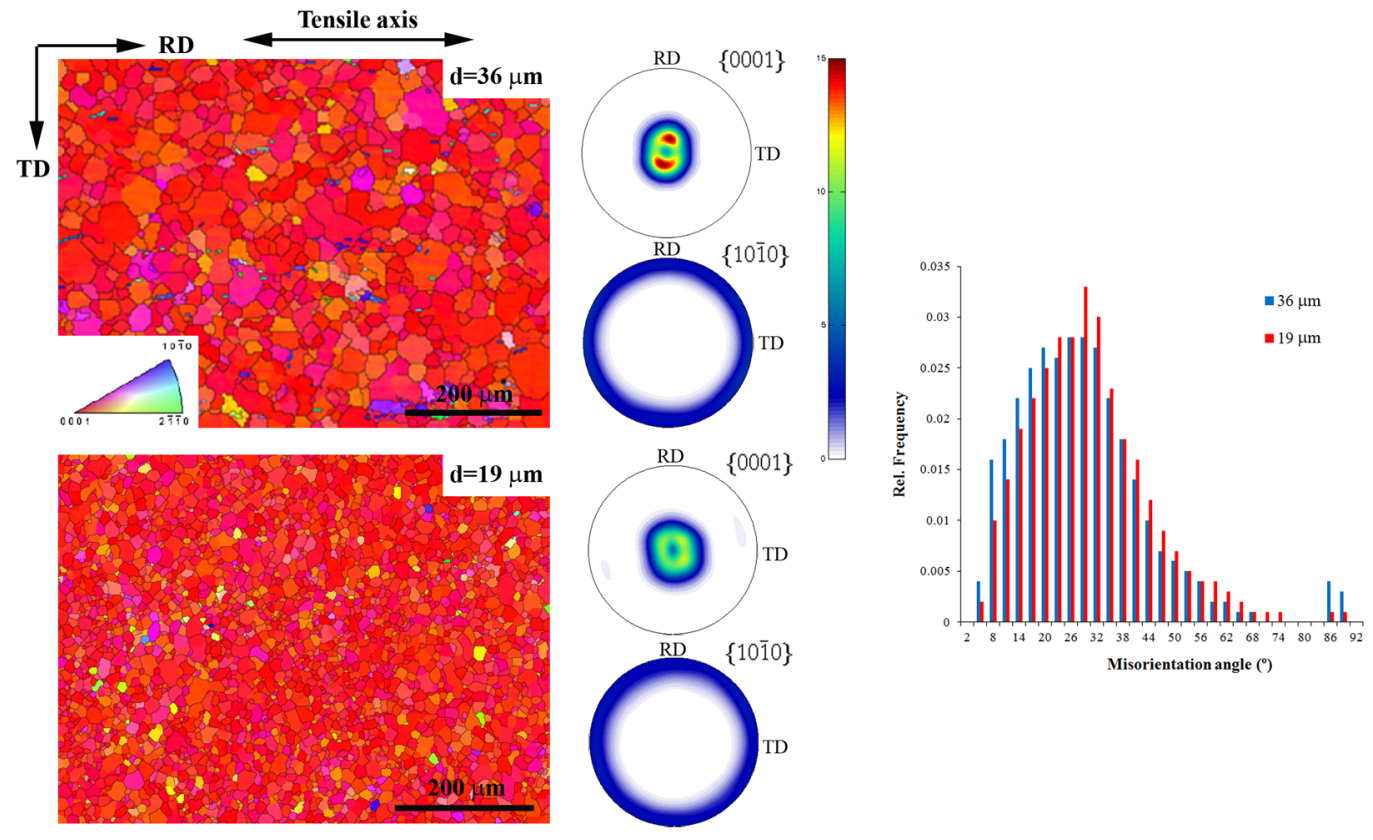

Fig. 1 Microstructure and texture of the two polycrystals investigated. EBSD IFP maps in the ND are plotted next to the corresponding XRD $\{0001\}$ and $\{10 \overline{1} 0\}$ pole figures and misorientation distribution histograms.

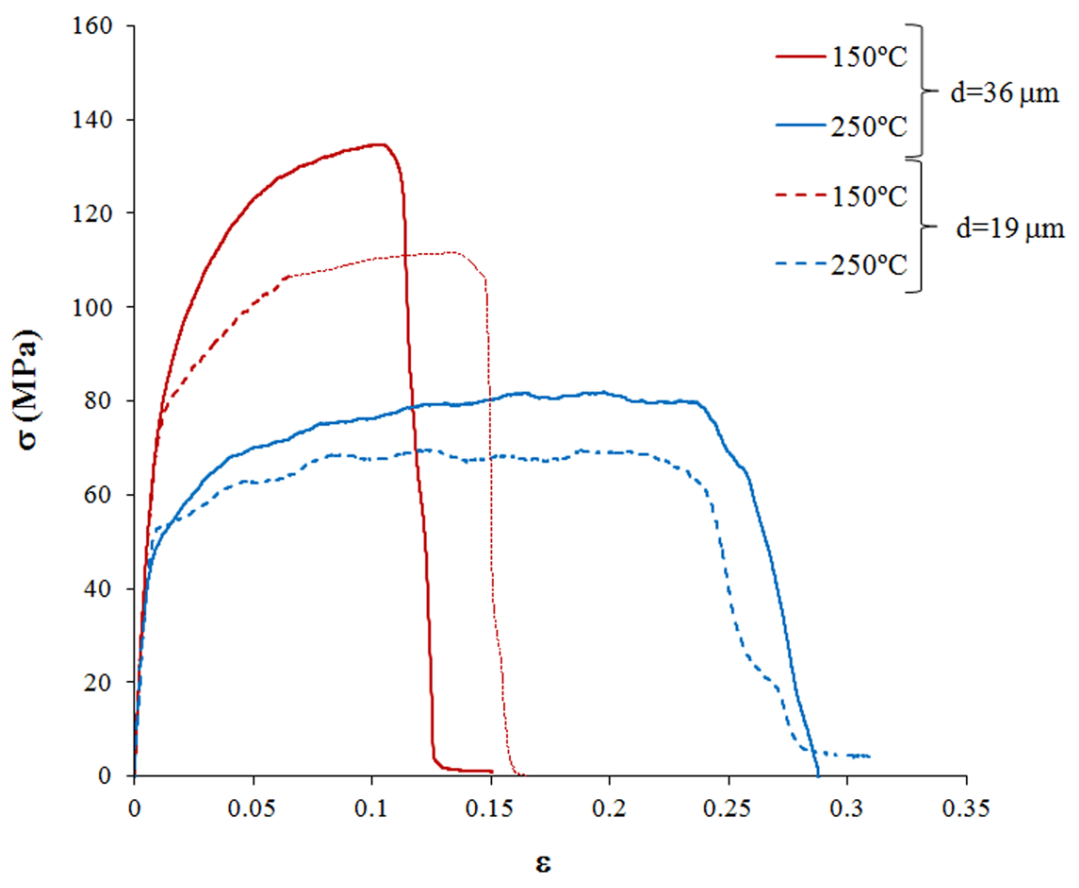

Fig. 2 Tensile true stress-true strain curves corresponding to the pure $\mathrm{Mg}$ polycrystals with $d$ values of $36 \mu \mathrm{m}$ and $19 \mu \mathrm{m}$ deformed at $150^{\circ} \mathrm{C}$ and $250^{\circ} \mathrm{C}$ and at an initial strain rate of $10^{-3} \mathrm{~s}^{-1}$. 


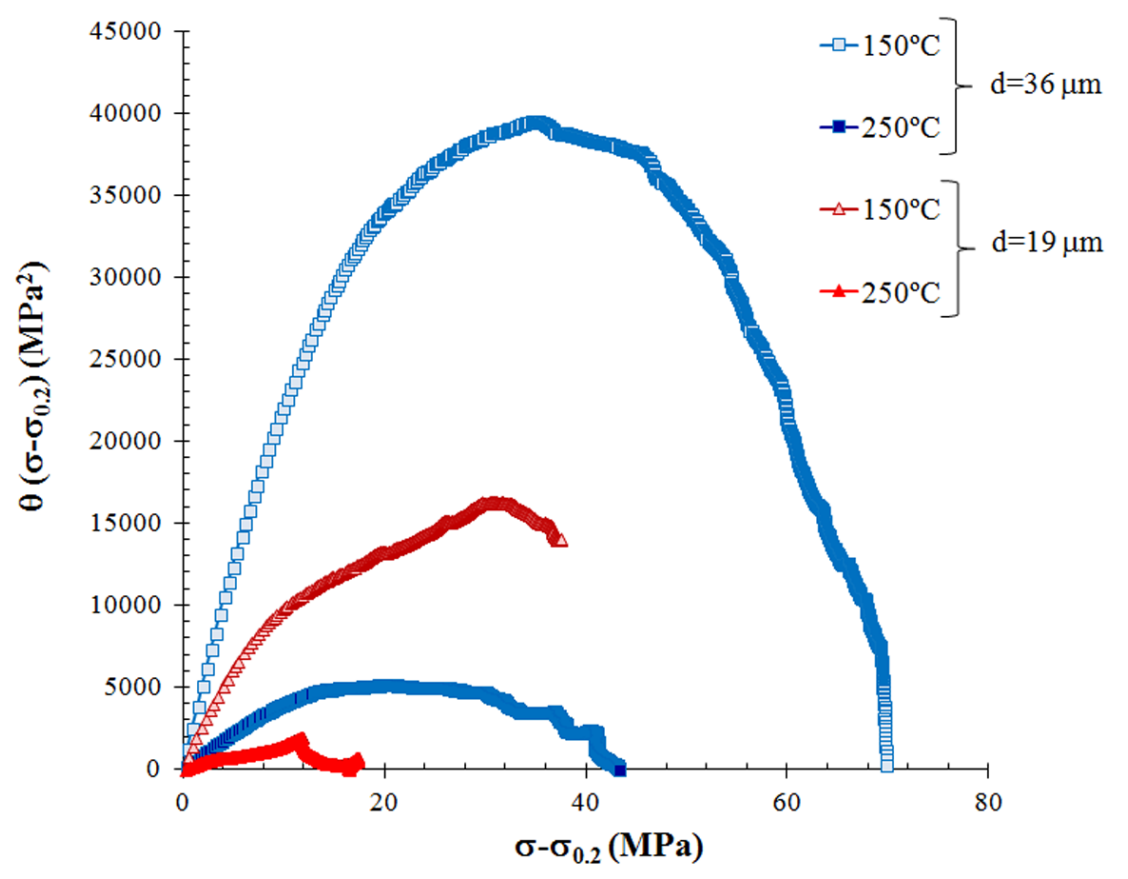

Fig. $3 \theta\left(\sigma-\sigma_{0.2}\right)$ vs. $\left(\sigma-\sigma_{0.2}\right)$ curves corresponding to the pure Mg polycrystals with $d$ values of $36 \mu \mathrm{m}$ and $19 \mu \mathrm{m}$ deformed at $150^{\circ} \mathrm{C}$ and $250^{\circ} \mathrm{C}$ and at an initial strain rate of $10^{-3} \mathrm{~s}^{-1}$.

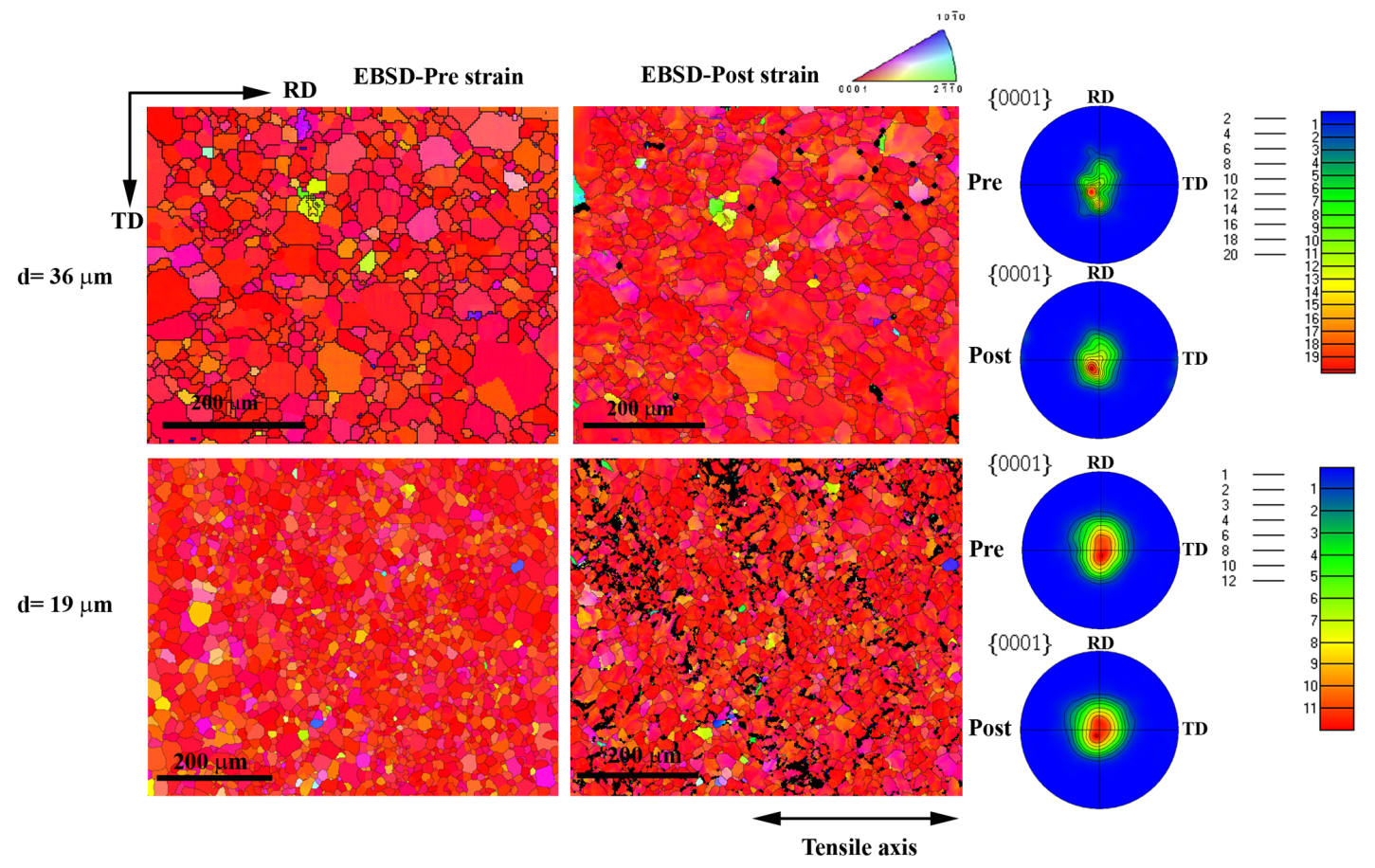

Fig. 4 EBSD IFP maps in the ND and the EBSD $\{0001\}$ pole figures corresponding to selected regions of the two polycrystals under study before testing at $250^{\circ} \mathrm{C}$ and after a strain of $10 \%$ at the same temperature. 


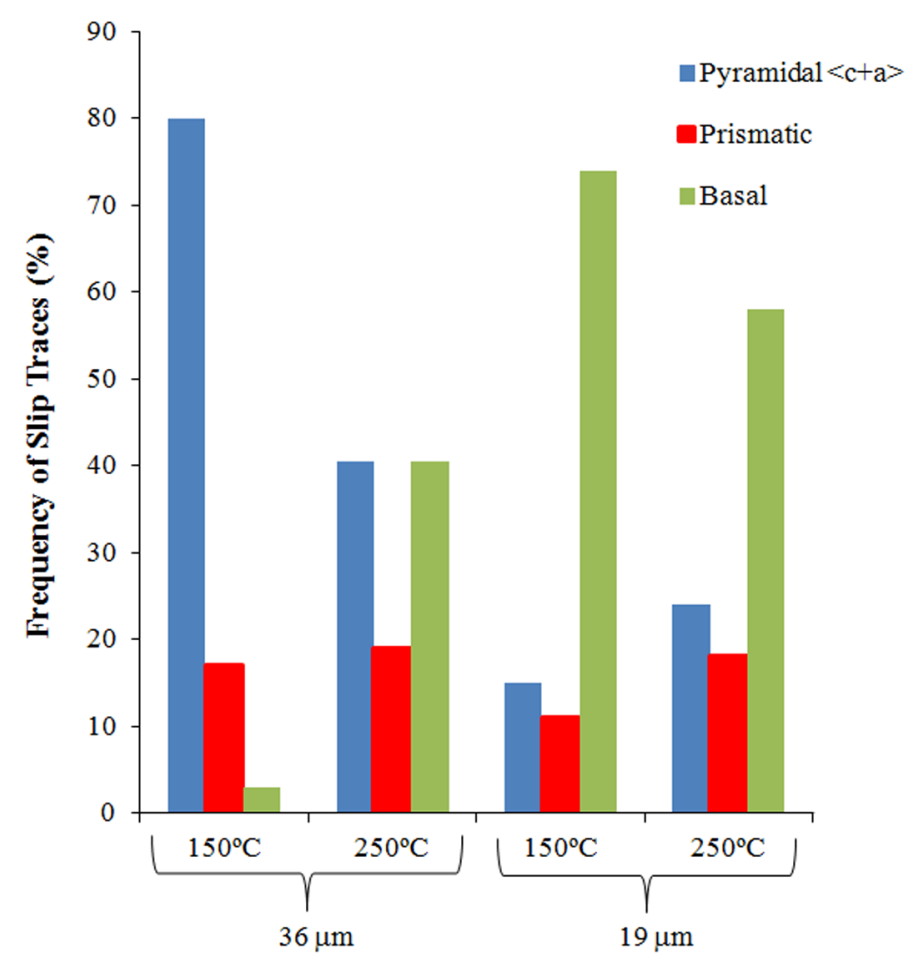

Fig. 5 Frequency of non-basal and basal slip traces in the two polycrystals investigated after tensile testing along $\mathrm{RD}$ at $150^{\circ} \mathrm{C}$ and $250^{\circ} \mathrm{C}$ and at an initial strain rate of $10^{-3} \mathrm{~s}^{-1}$ up to a strain of $\sim 10 \%$.

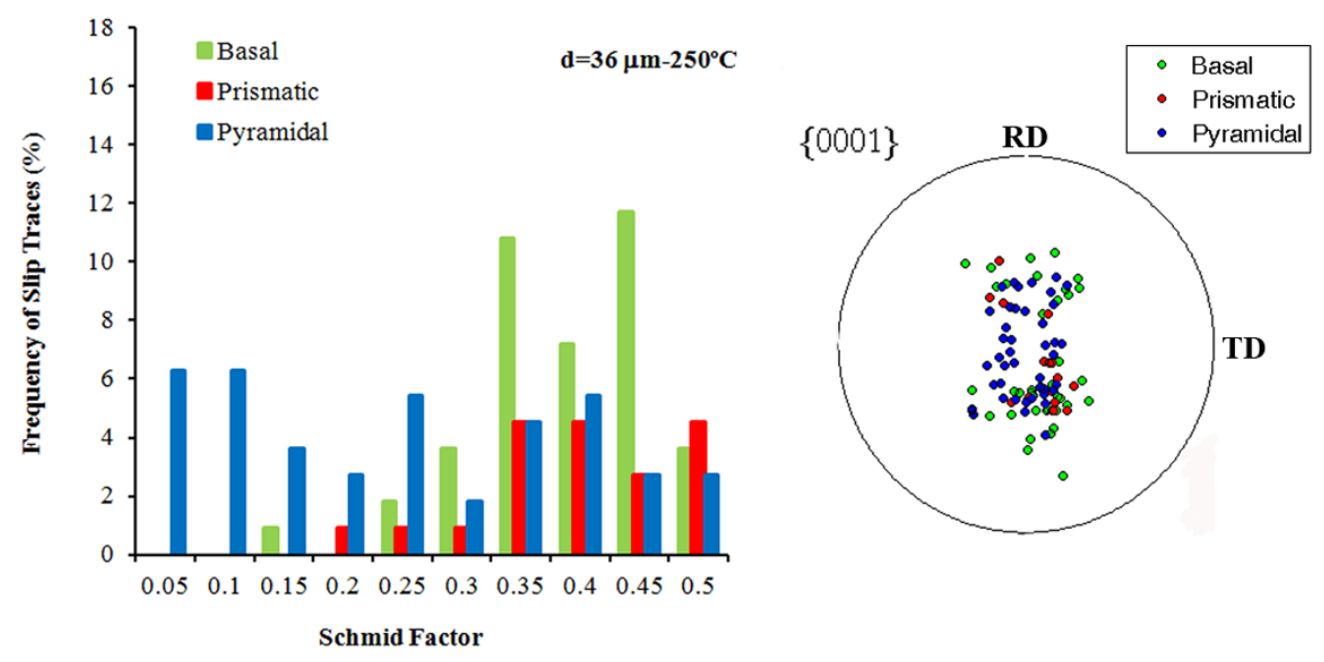

Fig. 6 Distribution of Schmid factors with respect to the global applied stress corresponding to the non-basal and basal traces detected in the pure $\mathrm{Mg}$ polycrystal with $d=36 \mu \mathrm{m}$ tested at $250^{\circ} \mathrm{C} ;\{0001\}$ discrete pole figure showing the orientation of the caxes of grains with pyramidal $<\mathrm{c}+\mathrm{a}>$ (blue dots), prismatic (red dots) and basal (green dots) traces. 


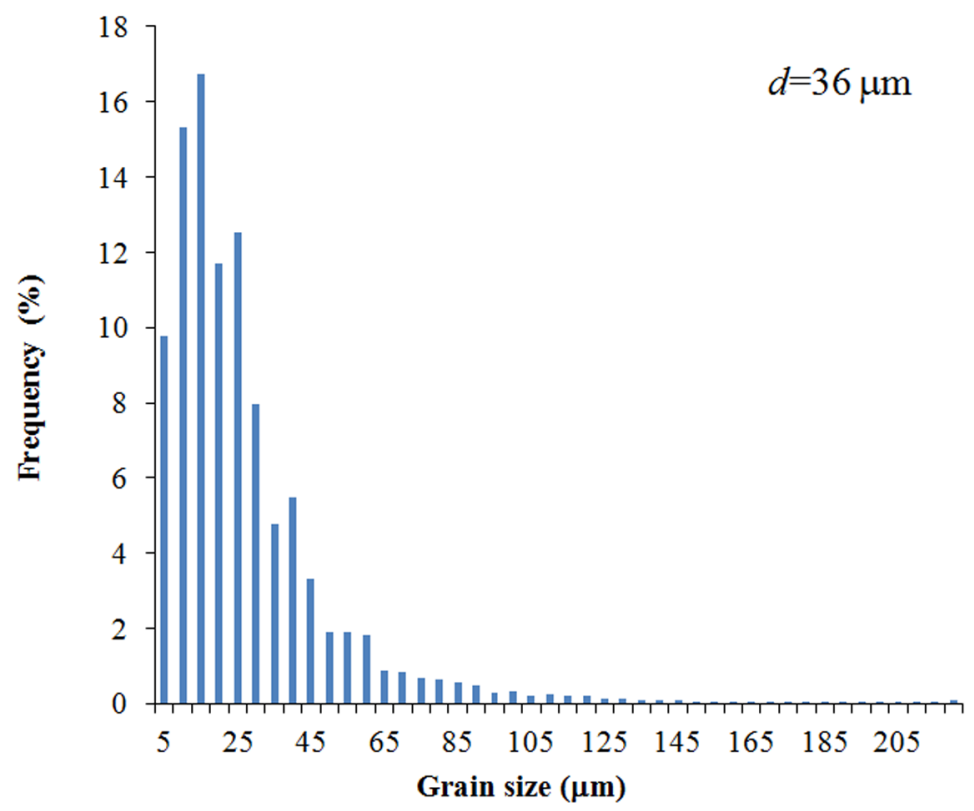

Fig. 7 Grain size distribution of the pure Mg polycrystal with $d=36 \mu \mathrm{m}$.

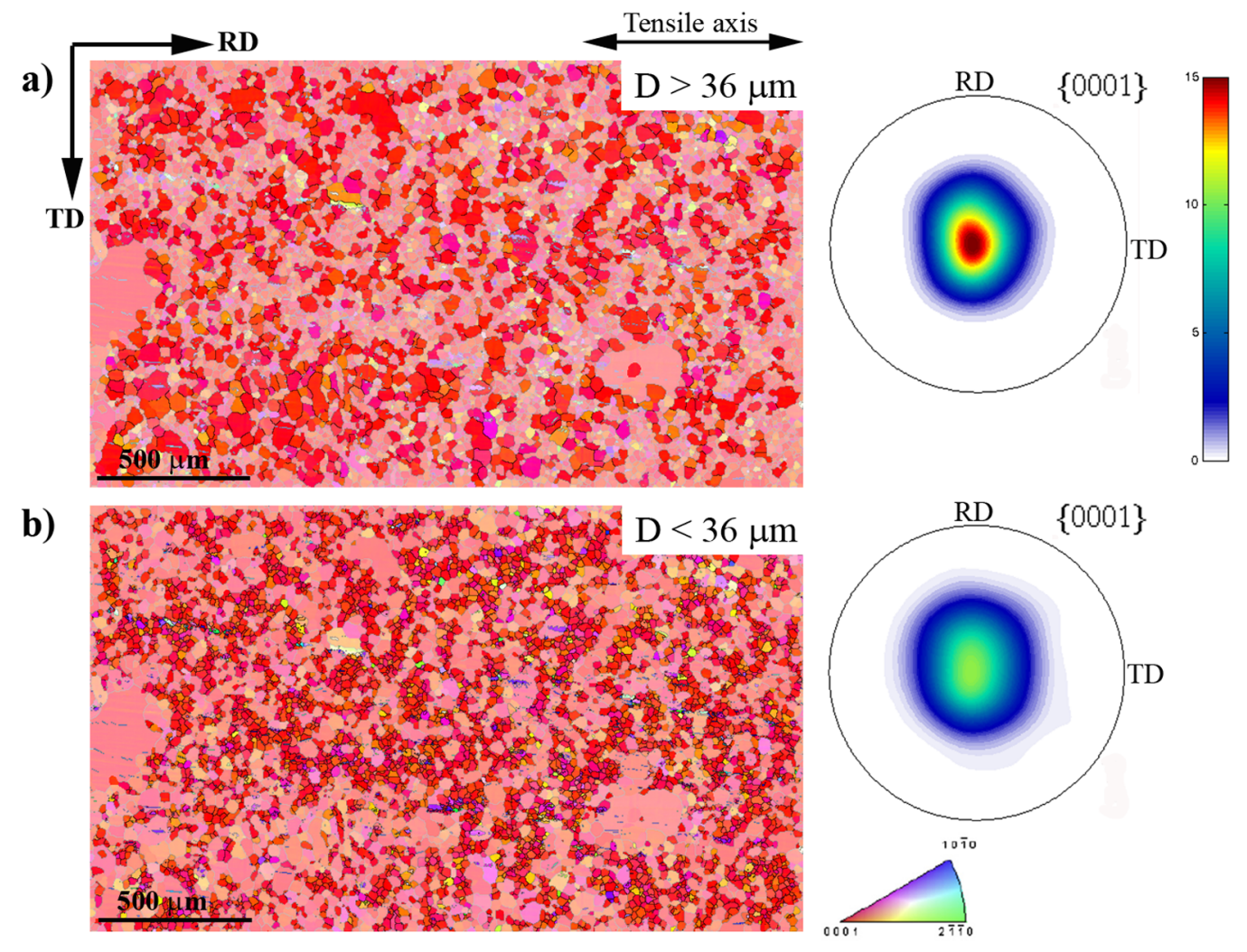

Fig. 8 Correlation between grain size (D) and texture in the coarser pure $\mathrm{Mg}$ polycrystal $(d=36 \mu \mathrm{m})$. EBSD IPF maps in the ND and $\{0001\}$ EBSD pole figures corresponding to (a) grains with $\mathrm{D}>d$ and (b) grains with $\mathrm{D}<d$. 


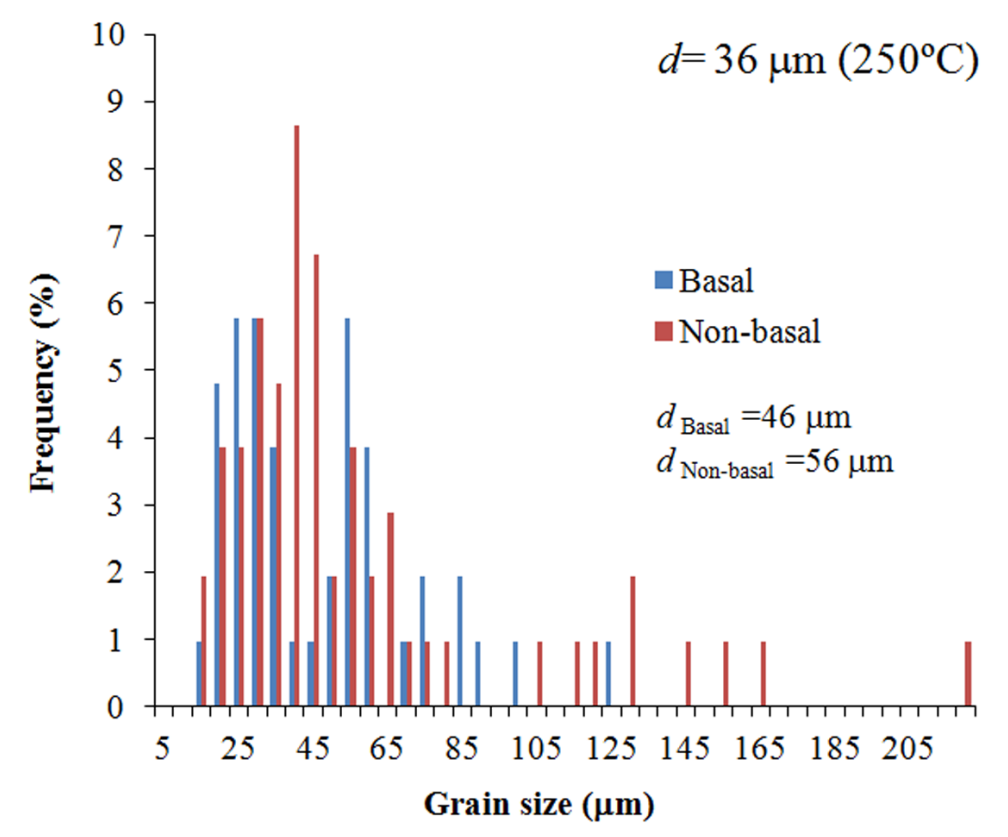

Fig. 9 Distribution of grain sizes in which non-basal and basal traces where detected in the polycrystal with $d=36 \mu \mathrm{m}$ tested at $250^{\circ} \mathrm{C}$.

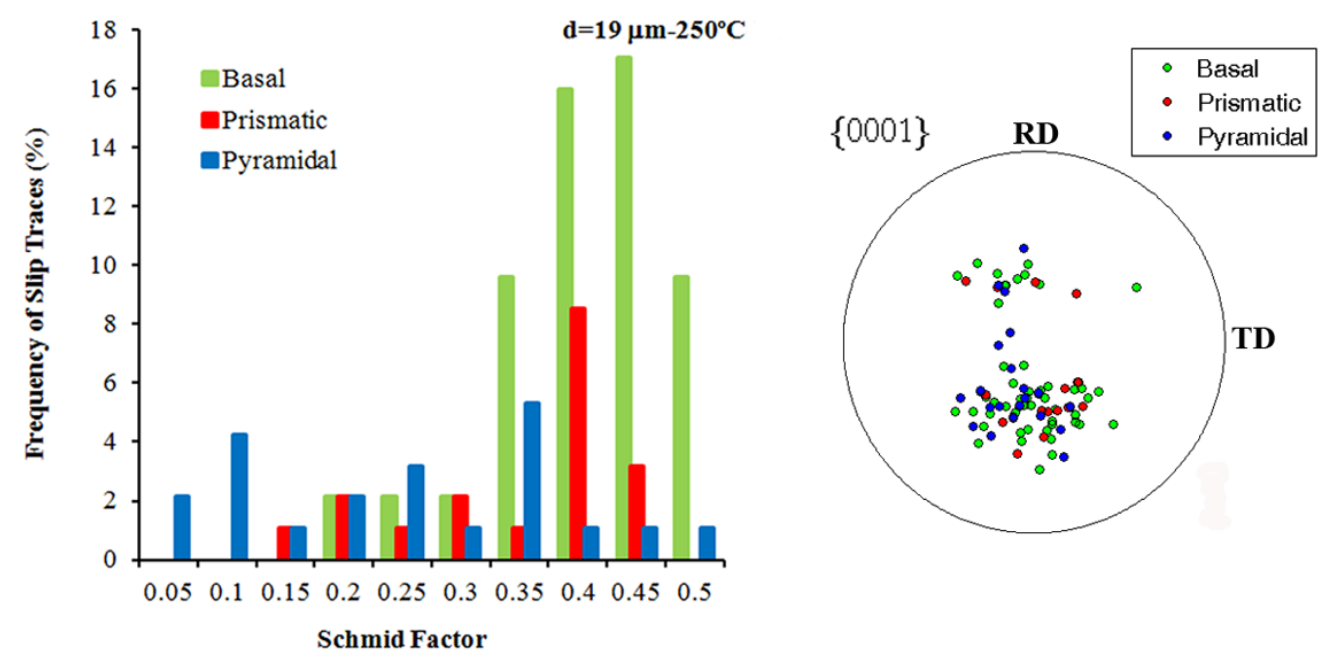

Fig. 10 Distribution of Schmid factors with respect to the global applied stress corresponding to the non-basal and basal traces detected in the pure $\mathrm{Mg}$ polycrystal with $d=19 \mu \mathrm{m}$ tested at $250^{\circ} \mathrm{C} ;\{0001\}$ discrete pole figure showing the orientation of the caxes of grains with pyramidal $<\mathrm{c}+\mathrm{a}>$ (blue dots), prismatic (red dots) and basal (green dots) traces. 


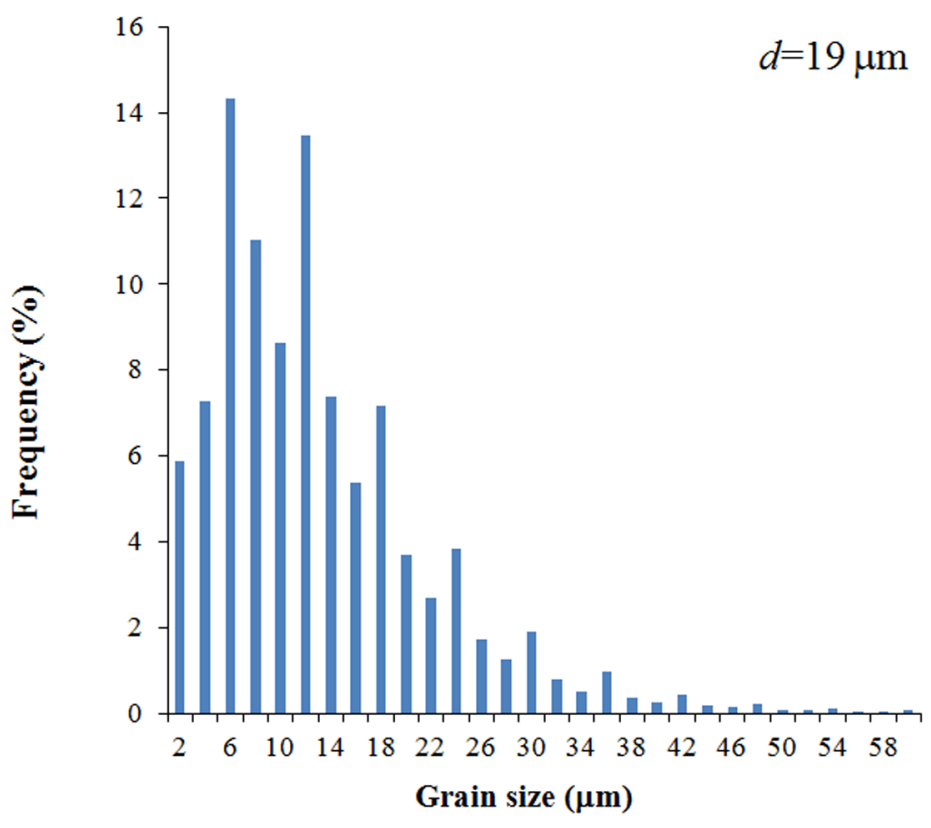

Fig. 11 Grain size distribution of the pure Mg polycrystal with $d=19 \mu \mathrm{m}$.
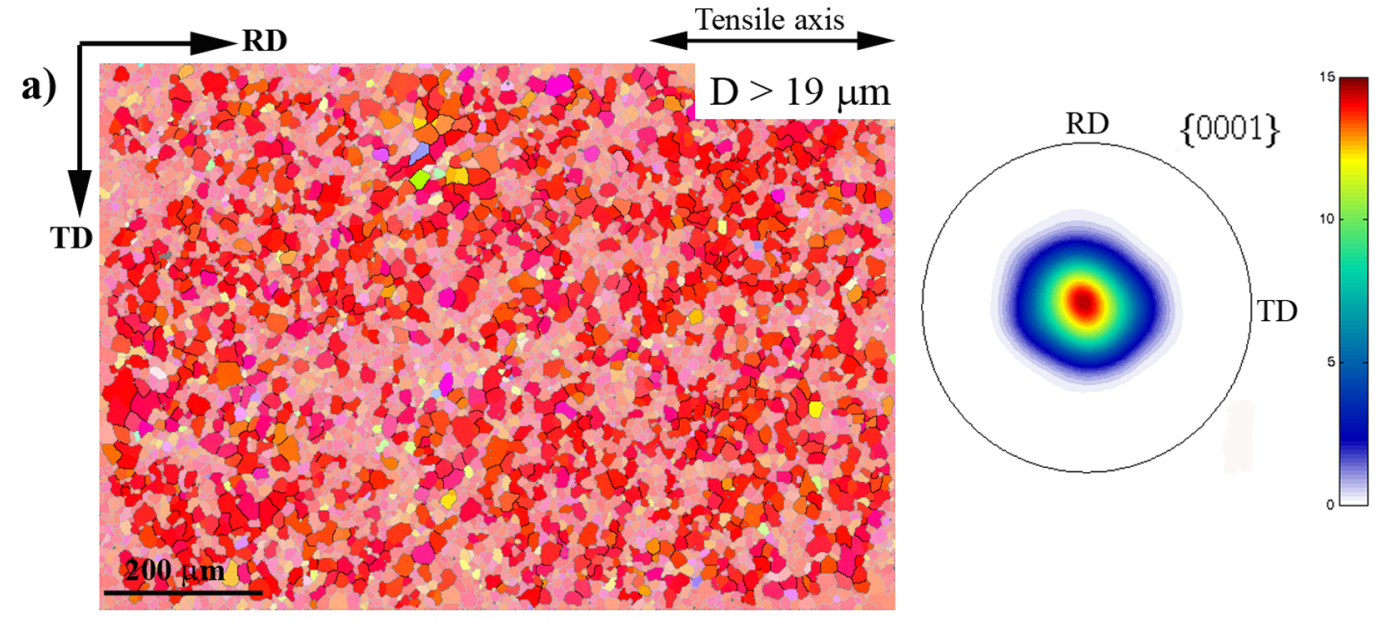

b)
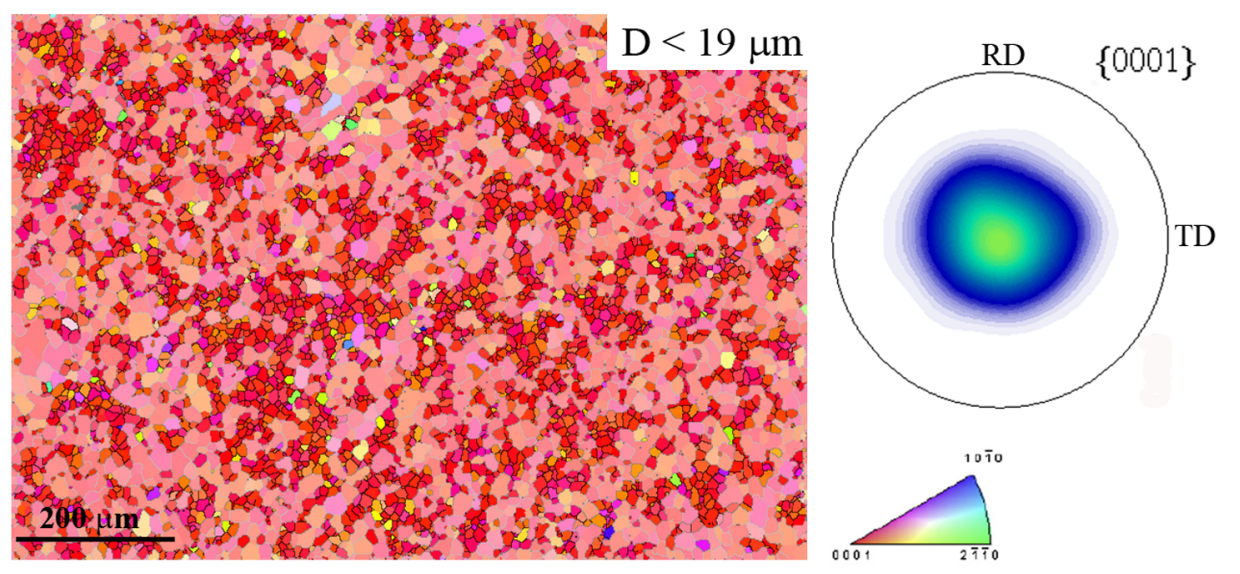

Fig. 12 Correlation between grain size (D) and texture in the finer-grained pure $\mathrm{Mg}$ polycrystal $(d=19 \mu \mathrm{m})$. EBSD IPF maps in the ND and $\{0001\}$ EBSD pole figures corresponding to (a) grains with $\mathrm{D}>d$ and (b) grains with $\mathrm{D}<d$. 


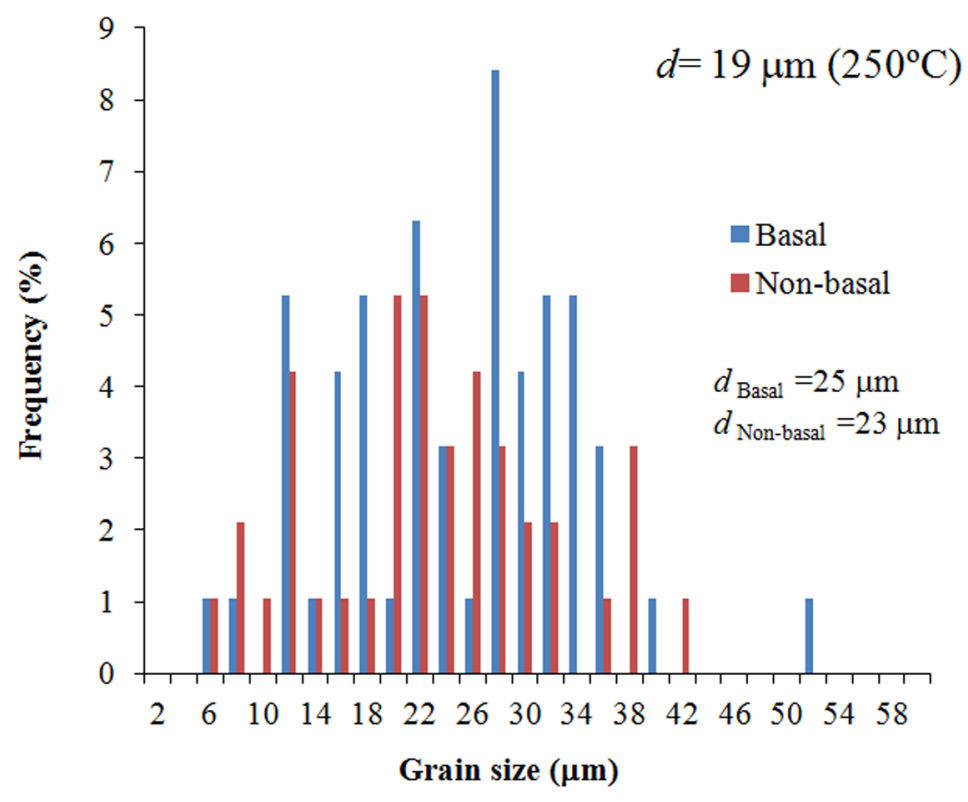

Fig. 13 Distribution of grain sizes in which non-basal and basal traces where detected in the polycrystal with $d=19 \mu \mathrm{m}$ tested at $250^{\circ} \mathrm{C}$.

a)

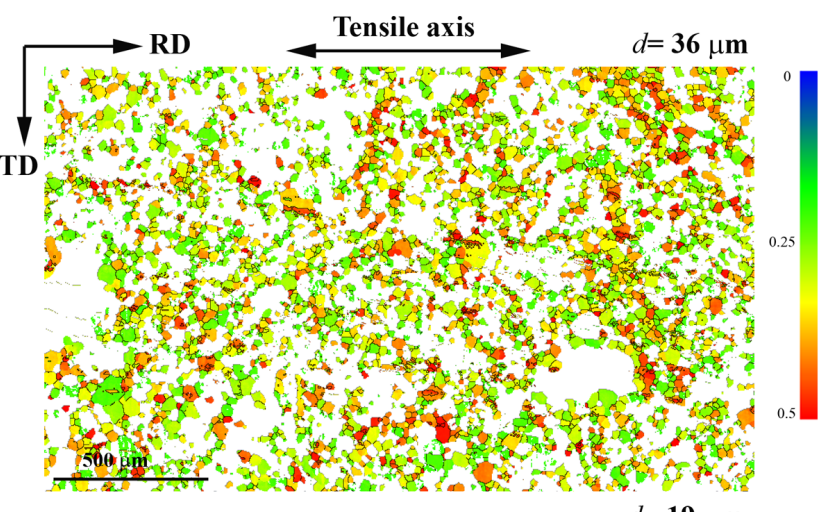

b)
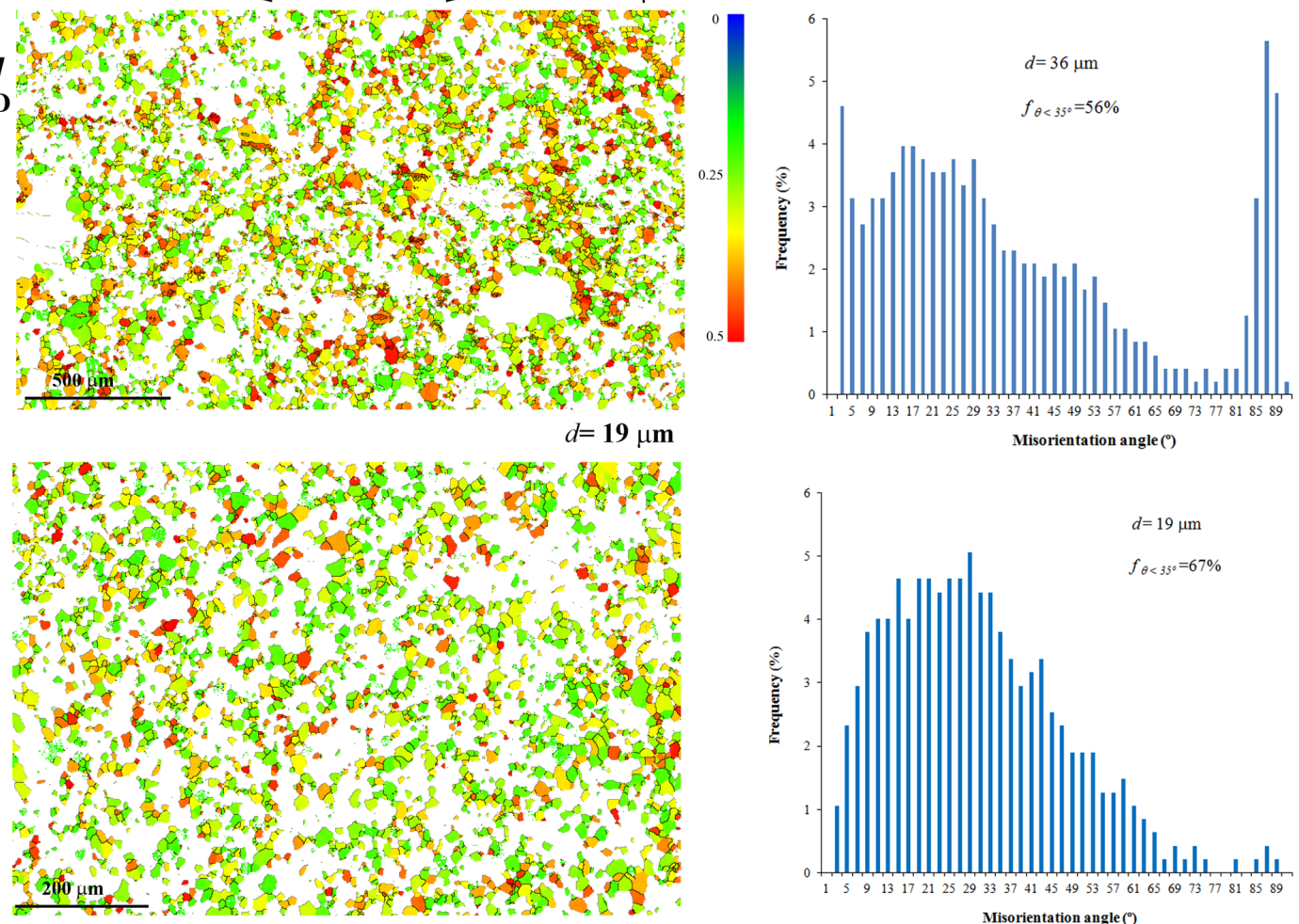

Misorientation angle $\left({ }^{\circ}\right)$

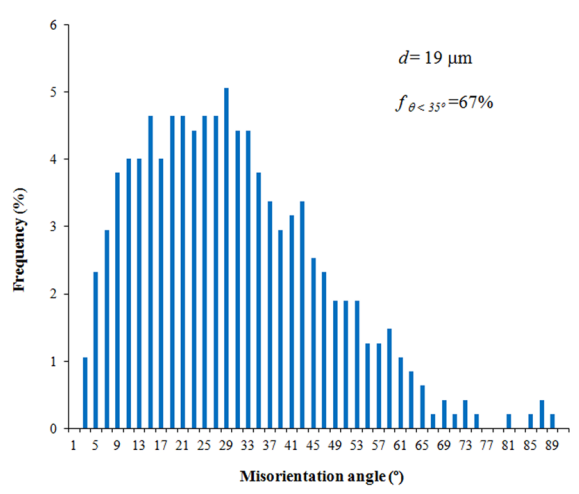

Fig. 14 EBSD showing the grains with $\mathrm{SF}_{\text {basal }}>0.2$ in the polycrystals with $36 \mu \mathrm{m}$ and $19 \mu \mathrm{m}$, as well as the corresponding misorientation distribution histograms. 

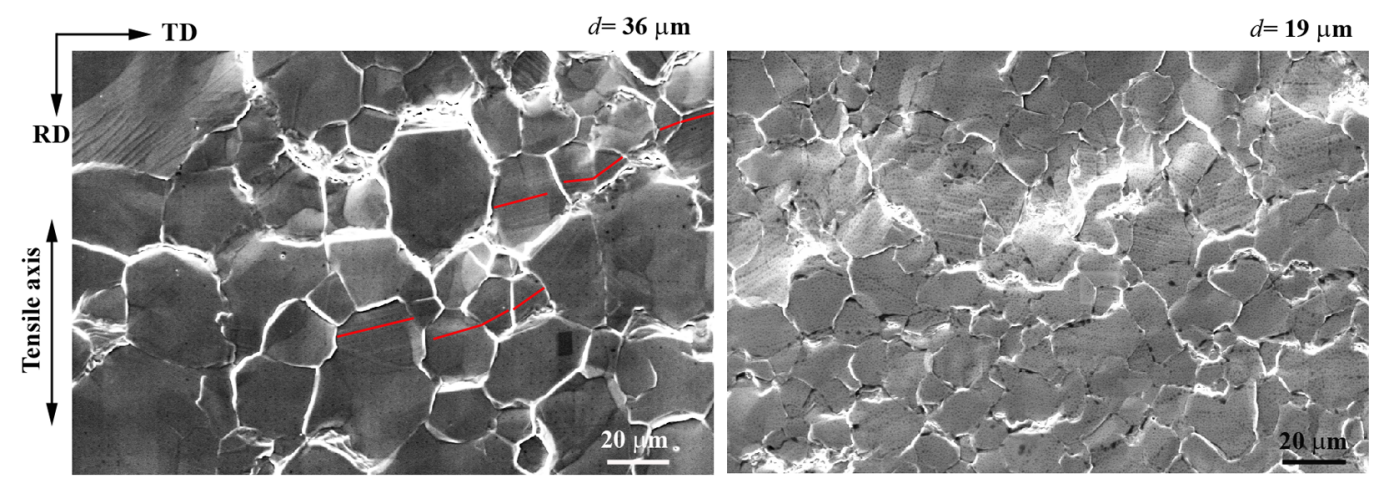

Fig. 15 SEM micrographs illustrating transfer of basal slip across boundaries in the polycrystals with $36 \mu \mathrm{m}$ and $19 \mu \mathrm{m}$.
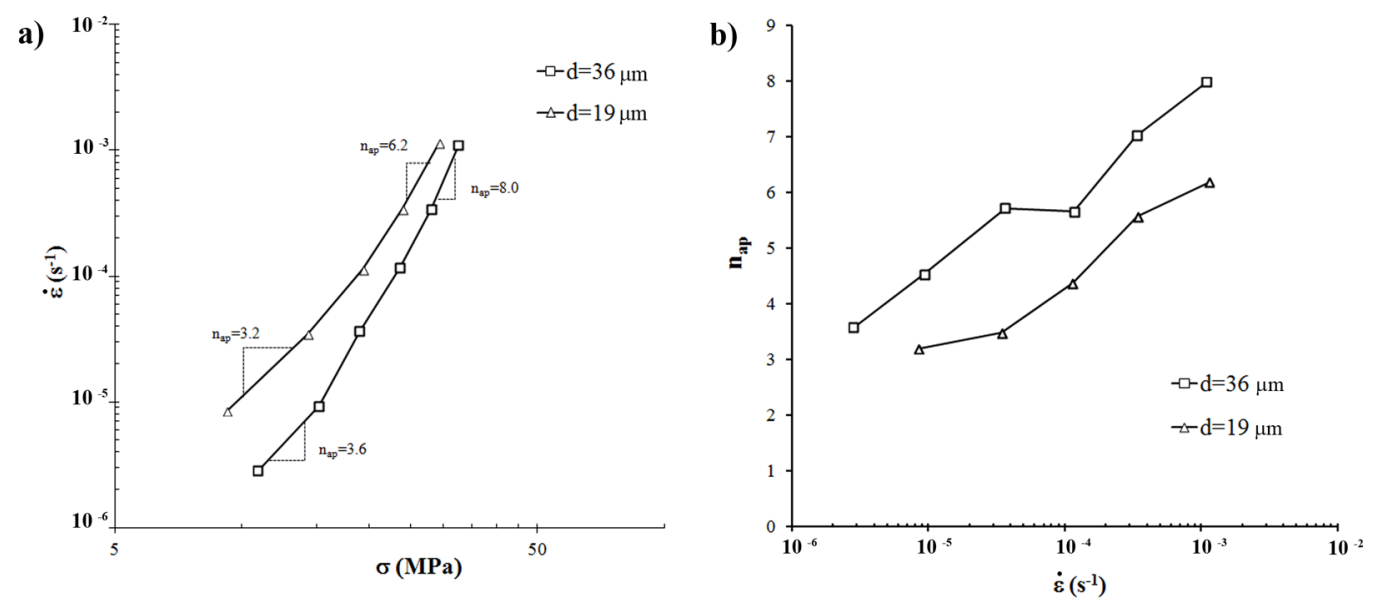

Fig. 16 (a) Evaluation of the stress exponents during tensile deformation along RD at $250^{\circ} \mathrm{C}$ in the two polycrystals under study. (a) $\log (\dot{\varepsilon})$ vs. $\log (\sigma) ;($ b) Variation of the apparent stress exponent with strain rate. 